\title{
Left ventricular dysfunction in chronic obstructive pulmonary disease
}

\author{
Saha B Kr ${ }^{1}$, Sarkar D. ${ }^{2}$, Sarkar L. ${ }^{3}$ Bandyopadhyay R. ${ }^{4}$ \\ ${ }^{1}$ Dr. Bikram Kr Saha, Assistant Professor. NBMC, Darjeelingat present at Malda Medical College. ${ }^{2}$ Dr. Debasis Sarkar, \\ Assistant Professor, Malda MCH, ${ }^{3}$ Dr. Liton Sarkar, Assistant Professor, RG Kar Medical College, ${ }^{4}$ Dr. Ramtanu \\ Bandyopadhyay, Professor, Malda MCH,West Bengal, India.
}

Corresponding Author: Dr. Debasis Sarkar, Assistant Professor, Malda Medical College, Malda WB, India. Email: dr.debasis99bmc@yahoo.in

\begin{abstract}
Introduction: The prevalence of LV dysfunction is probably high in COPD patients because this condition shares common risk factors. The diagnosis of left heart failure is difficultin the early phases of COPD and also during exacerbation due to similarities in signs and symptoms. Bio-markers like hsCRP is found to be elevated in stable phase as well as in exacerbation of COPD. Objectives: To assess LV Dysfunction (Systolic and Diastolic) and to correlate Age, Symptoms, Duration and stage of illness, CRP with LV Dysfunction. Methods: Total 100 patients of which 50 were age and sex matched controls not having COPD complying with Inclusion and Exclusion Criteria. After taking history and clinical examination they were evaluated for COPD and Left ventricular Dysfunction using PFT and Echocardiogram. Results: Out of 50 patients, 37 patients (74\%) had Diastolic dysfunction, of them 2 patients had Systolic dysfunction also. 13 patients were normal. In the control group only 4 had Diastolic Dysfuncion.CRP was high in 35\% (70\%) of patients. In the higher age group of 50-60 years Diastolic dysfunction was significant. In patients of GOLD stage IV 5 out of 5 patients $(100 \%)$ whereas in GOLD stage I and II it was in 1 case $(16.66 \%)$ and21 case $(80.76 \%)$ respectively. While comparing with the control group incidence of LV dysfunction parameters and CRP is more in case group. Conclusion: There is increased incidence ofLV Diastolic dysfunction and also with advanced GOLD stage. CRP also correlates well LVDD. Therefore it is pertinent to explore LVDD in all patients with acute exacerbation of COPD and advanced disease stage.
\end{abstract}

Keywords: COPD, Left Ventricular Dysfunction, Diastolic Dysfunction.

\section{Introduction}

Chronic Obstructive Pulmonary Disease (COPD) is a major cause of Chronic Morbidity and Mortality worldwide. It is the fifth leading cause of death world wide [1]. Acute exacerbation of COPD (AECOPD) accounts for large amounts of the Morbidity and Mortality attributed to COPD [2]. AECOPD refers to the exaggeration of COPD symptoms: aggravation of dyspnoea, an increase in expectoration volume, and a change in the appearance of sputum which becomes purulent [3]. Although dominated by bacterial or viral infection, etiologies of AECOPD remain unrecognised in as much as one third of these patients [4].

Added to this, acute left ventricular (LV) dysfunction is suspected as a cause of exacerbation in many such patients. Never the less in many of these situations LV

Manuscript received: $10^{\text {th }}$ October 2018

Reviewed: $20^{\text {th }}$ October 2018

Author Corrected: $26^{\text {th }}$ October 2018

Accepted for Publication: $30^{\text {th }}$ October 2018 dysfunction might be associated without being the cause of the exacerbation. Yet a diagnosis of LV dysfunction in patients with dyspnoea is challenging to the emergency department physicians, because bed side clinical assessment has a poor performance record and cardiac function test with enough accuracy to diagnose (in particular echo-cardiography) are not always possible because they are unavailable or difficult to interpret [5]. The prevalence of LV dysfunction is probably high in COPD patients because this condition shares many risk factors with coronary disease: age, male predominance, cigarette smoking and so on [6].

The diagnosis of left heart failure is fraught difficult notably in the early phases of COPD and also during exacerbation due to similarities in signs and symptoms. Importantly co-existence of COPD and heart failure is plausible in view of overlap of risk factors: notably smoking. Echocardiography is essential for establishing 


\section{Original Research Article}

the diagnosis of heart failure. Accessibility to this diagnostic facility however is limited for primary care patients and echocardiography is not a part of the standard investigational protocol of pulmonologists. It seems therefore plausible that a considerable proportion of patients with a diagnosis of COPD have concomitant heart failure which remains unrecognized by primary care physicians or pulmonologists. In addition, due to similarities in symptoms some COPD patients may be misclassified and in fact have heart failure. Earlier studies suggested that the use of pulmonary medication often coincides with unrecognized heart failure $[7,8]$.

The prevalence of heart failure can be as high as $20 \%-$ $30 \%$ in those COPD patients who are referred for acute exacerbation. $[9,10]$. However information is lacking on the prevalence of left heart dysfunction as a cause of left heart failure in the much larger population of patients with stable COPD. Development of right ventricular hypertrophy and eventual right heart failure is also quite common in patients of COPD. However, some disturbance in left ventricular function has been observed by several workers among such patients. The present study is undertaken with a view to determine the degree of disturbance in left ventricular function if any, among patients of COPD. Bio-markers like hsCRP is found to be elevated in stable phase COPD patients and Brain Natriuretic Peptide (BNP) and amino terminal Pro-brain Natriuretic Peptide have been shown to perform well in distinguishing between dyspnea of cardiac origin and dyspnoea of pulmonary causes in patients attending emergency department [11-16].

However extrapolation of these results to the specific context of AECOPD is not straight forward because BNP secretion might be secondary to left ventricular stress or right ventricular stress. [17,18].

In this study we have also tried to find out the prevalence of raised CRP in those patients of COPD with LV dysfunction. Traditional texts and review articles suggest that dyspnoea due to COPD can be readily distinguished from LVF by clinical, radiographic and spirometric abnormalities. COPD may obscure clinical signs of LVD, both disorders may produce paroxysmal nocturnal dyspnoea, orthopnoea and cough.

Radiographic and clinical findings of pulmonary congestion and cardiomegaly may be obscured by large barrel chest and hyper-inflated lungs of patient with emphysema. Evidence of airway obstruction and a bronchodilator response on pulmonary function test is found not only in COPD, but also in acute congestive failure [19-21]. Hence in this present study we tried to show the prevalence of LVD co-existent with COPD in the absence of factors known to produce LVD.

\section{Objectives}

1.To assess LV Dysfunction(Systolic and Diastolic).

2.To correlate Age, Symptoms, Duration and stage of illness, CRP with LV Dysfunction.

\section{Methods}

a) Study Type: Cross-sectional Analytical Study.

b) Sample Size: 100 patients with Left ventricular Dysfunction were enrolled.

c) Sampling Technique: Consecutive Non-probability sampling technique used.

d) Inclusion Criteria:Any patient with COPD between $50-65 y$ ys. The upper age limit is 65 yrs since above that; sizeable number of otherwise normal persons can develop diastolic dysfunction.

e) Exclusion Criteria: Acute myocardial infarction within 6 weeks, Severe congestive cardiac failure, Hypertension, Diabetes, Valvular Heart Diseases, Known patient of Cardiomyopathy.

f) Procedure: After taking approval from Hospital ethical Committee, written informed consent were taken from patients. 50 patients with COPD admitted in Medicine Indoor and 50 age and sex matched patients not having COPD were enrolled in this study. A detailed history followed by clinical examination were documented as per proforma. PFT, Chest X-ray, ECG, Echocardiogram to document Systolic and Diastolic Dysfunction and CRP in blood examination were done. Transthorasic Echocardiogram was done wherever necessary. Echocardiographic analysis

The echocardiograph device was an Envisor $\mathrm{C}$ model (Philips Medical Systems, Andover, Massachusetts, USA) equipped with a $2.0-4.0 \mathrm{MHz}$ probe capable of capturing second harmonic, tissue, pulsed, continuous and color Doppler traces, as well as one- and twodimensional mode images. With participants positioned in left lateral decubitus and monitored using an electrocardiographic lead, the following Echocardiographic cuts were performed: short parasternal axis to measure ventricles, aorta and left atrium and apical two, four and five chambers to evaluate cavities and systolic and diastolic functions of ventricles. All of the 


\section{Original Research Article}

measurements were performed in accordance with the American Society of Echocardiography/ European Association of Echocardiography recommendations. An average of three measurements was calculated for each variable.

The left ventricular (LV) mass (LVM) was calculated according to the following formula: $L V M=0.8 \times\{1.04 \times$ [(LVDD+IVSDT+PWDT)3-LVDD3] $\}+0.6, \quad$ where LVDD, IVS and PWDT represent the LV diastolic diameter, interventricular septum and posterior wall thickness, respectively. The left ventricular systolic function was evaluated by measuring the ejection fraction (EF) according to the Teichholz method.

The LV diastolic function was evaluated by measuring the early (E wave) and late (A wave) diastolic mitral inflow velocities, their ratio, the $\mathrm{E}$ wave deceleration time (EDT) and the isovolumic relaxation time (IVRT).

\section{Results}

Table 1: Diastolic dysfunction in cases vs controls.

\begin{tabular}{|c|c|c|c|}
\hline 2 & \multicolumn{2}{|c|}{$\begin{array}{l}\text { No of patients having Diastolic } \\
\text { dysfunction }\end{array}$} & percentage \\
\hline 50 (cases) & \multicolumn{2}{|c|}{37} & $74 \%$ \\
\hline 50 (controls) & \multicolumn{2}{|c|}{04} & $8 \%$ \\
\hline \multicolumn{4}{|c|}{ CRP } \\
\hline & \multicolumn{2}{|c|}{ No of patients } & Percentage \\
\hline$>0.60$ & \multicolumn{2}{|c|}{35} & $70 \%$ \\
\hline$<0.60$ & \multicolumn{2}{|c|}{15} & $30 \%$ \\
\hline \multicolumn{4}{|c|}{ GOLD Stage \& Diastolic dysfunction } \\
\hline & No of patient & DD & Percentage \\
\hline 1 & 6 & 1 & $16.66 \%$ \\
\hline $2 \mathrm{~A}$ & 26 & 21 & $80.76 \%$ \\
\hline 3 & 13 & 10 & $76.92 \%$ \\
\hline 4 & 5 & 5 & $100 \%$ \\
\hline \multicolumn{4}{|c|}{ CRP \&Diastolic dysfunction } \\
\hline & N0 of patient & DD & Percentage \\
\hline$>.60$ & 35 & 34 & $97.14 \%$ \\
\hline$<.60$ & 15 & 3 & $20 \%$ \\
\hline \multicolumn{4}{|c|}{ CRP in cases and controls } \\
\hline \multicolumn{2}{|c|}{ Cases (Mean+/-SD) } & Controls (Mean+/-SD) & P Value \\
\hline \multicolumn{2}{|c|}{$0.699+/-0.184$} & $0.414+/-0$ & $<0.001$ \\
\hline
\end{tabular}

In our study, we found that Diastolic dysfunction is a significant occurrence in the case arm than among control arm.CRP is also significantly raised in COPD patients ( $p$ value $<0.001)$ and in patients having raised CRP have diastolic dysfunction too ( $p$ value 0.0000 i.e $<0.05$ ).Comparing the presence of diastolic dysfunction in early stage i.e. 1 and in advanced stage i.e. 4 we find that the association between stage 4 disease and diastolic dysfunction is significant $(\mathrm{P}=$ 0.0057 i.e. $<0.05)$.

Table 2: Various parameters of LV Functions in cases vs controls

\begin{tabular}{|c|c|c|c|}
\hline Indices of LVD & Cases $($ Mean+/-SD) & Controls (Mean+/-SD) & P Value \\
\hline E/A & $0.964+/-0.257$ & $1.218+/-0.135$ & $<0.001$ \\
\hline DT & $242+/-14.424$ & $230.44+/-8.836$ & $<0.001$ \\
\hline IVRT & $94.2+/-9.029$ & $80.88+/-7.862$ & $<0.001$ \\
\hline EF & $60 \%+/-0.062$ & $60 \%+/-0.029$ & $>0.001$ \\
\hline
\end{tabular}

We find that each parameter of DD (E/A, DT, IVRT) to be abnormal in the case group we find that each parameter of DD is significant $(\mathrm{P}<0.001)$ in the case group, whereas parameter of SD $(\mathrm{EF})$ is not significant $(\mathrm{P}>0.001)$. 


\section{Discussion}

In the present study we have found presence of LVD in COPD patients and have found that majority of them have Diastolic dysfunction and that it is a significant occurrence $(p<0.001)$ in them. In our study, also we got diastolic dysfunction in the control group; however comparing two groups we found DD is more prevalent in patients with COPD.

In our study we found dyspnoea to be the predominant symptom. Although some studies indicate a weak relationship between the symptoms of dyspneoa and indicators of disease severity (FEV, LVEF)[22-24], there also exist some other studies which indicate that no relationship is evident between them $[22,25,26]$. We too did not find any significant association between this predominant symptom of dyspneoa and DD ( $p>0.05)$.

Funk GCet alreported that the maximal atrial filling velocity was increased and the early filling velocity was decreased in patients with COPD compared to control subjects [27]. The early flow velocity peak/late flow velocity peak (E/A) ratiomarkedly decreased in patients with COPD compared to control subjects $(0.79+0.035$ vs $1.38+0.069$, respectively; $\mathrm{p}<0.0001)$, indicating the presence of left ventricular diastolic dysfunction. The atrial contribution to total left diastolic filling was increased in patients with COPD. This was also observed in COPD patients with normal PAP, as ascertained using a right heart catheter. The atrial contribution to total left diastolic filling was further increased in COPD patients with higher PAP. PAP correlated with the $\mathrm{E} / \mathrm{A}$ ratio $(\mathrm{r}=-0.85 ; \mathrm{p}<0.0001)$.

In our study also, early flow velocity peak/late flow velocity peak (E/A) ratio was markedly decreased in patients with COPD compared to control subjects (cases $0.964+0.257$ vs. controls $1.218+0.135$ respectively; $p$ $<0.001)$ and the values of DT and IVRT were increased in them compared to control subjects (cases $242+$ 14.424 vs. controls $230.44+8.836$ and cases $94.2+$ 9.029 vs. controls $80.88+7.862$ respectively; $\mathrm{p}<0.001$ )

In our study too we founda trial contribution to total left diastolic filling was further increased in COPD patients with higher PAP as we saw the occurrence ofP Pulmonale, an ECG marker of pulmonary hypertension to be significant in the cases having DD $(\mathrm{p}<.05)$. Suchoń Eet alreported in COPD patients LV diastolic function is significantly impaired and its magnitude is related with increase in pulmonary artery pressure, while systolic LV function is well preserved [28]. In our subset of patients we observe that there is increase prevalence of DD but only in two patients we got systolic dysfunction (SD) which is not significant statistically. As we have excluded patients with known myocardial infarction, ischaemic heart disease, dilated cardiomiopathy, so cause of SD in these two patients cannot be confirmed. To find out hidden ischaemic heart disease or myocardial disease, cardiac catheterization, coronary angiography or myocardial biopsy were necessary but these procedures were out of our reach. Regarding patients who have echo proved DD, we found DD is more prevalent in the higher age group, however since age related myocardial changes occur in normal person's without COPD, and age related increased occurrence were reported in the case arm also.

DD is more prevalent in our study in patients whose duration of symptoms was more than 5 years. This observation is significant $(p<0.05)$ among the cases. DD is found to be more prevalent in those who presented with predominant dyspnoea. However statistical analysis fails to show any significant association between symptom nature and DD ( $p>0.05)$

Another salient feature in our study is that significant occurrence of DD in the advanced stage of COPD i.e. GOLD STAGE IV than in early stage of the disease i.e. GOLD STAGE I, probably higher presence of pulmonary hypertension and right ventricular strain by the virtue of inter ventricular dependence accounts for this observation.

In our study we found raised CRP, is a significant occurrence among DD patients in the case arm. However, though traditional studies depict hsCRP to be raised in COPD patients due to scarcity of resources we used ordinary CRP as an alternative. Raised CRP in the COPD patients in our study is not solely due to chest infection in these patients since initially they were all stabilized with nebulization and antibiotics; they represent an inflammatory nature of the disease itself and a plausible cause of their significant association with DD may be the contribution of this inflammatory process in atherogenesis thereby giving rise to microvascular ischemia to the cardiac muscle.

Kirsten Jörgensenet al reported LV in patients with severe emphysema is hypovolemic,and operates on a steeper portion of the LV function curve, while indices of systolic function are not significantly impaired compared to non-emphysematous controls. 


\section{Original Research Article}

A. K. Poddar et al [29]. Reported parameters of LVD like MRCF, EF, FS were depressed in the subset of patients of COPD with Corpulmonale and overt right heart failure while in patients of COPD with Corpulmonale only the parameters of LVD were intact. However, our finding is that diastolic dysfunction is present in majority of patients of COPD without any features of overt failure i.e in stable phase COPD.

\section{Conclusion}

Left ventricular diastolic dysfunction is significantly present in COPD patients more in those with Older age, Long symptom duration, Advanced stage of disease, Pulmonary hypertension and Raised CRP level.

Facts regarding raised CRP level: It is nothing new to know that, COPD is a systemic and inflammatory disease. Like any other inflammatory disease, CRP is also raised in our study. The inflammation is giving rise to atherogenesis and microvascular ischaemia leading to diastolic dysfunction. This data only reinforces the current knowledge of association between raised CRP, inflammation and microangiopathy.

Funding: Nil, Conflict of interest: None Permission of IRB: Yes

\section{References}

1. Pauwels RA, Rabe KF. Burden and clinical features of chronic obstructive pulmonary disease (COPD). Lancet. 2004 Aug 14-20;364(9434):613-20.

2. Miravitlles M, Murio C, Guerrero T, Gisbert R; DAFNE Study Group. Decisionessobre Antibioticoterapiay Farmacoeconomíaen la EPOC. Pharmacoeconomic evaluation of acute exacerbations of chronic bronchitis and COPD. Chest. 2002 May; 121 (5): 144955 .

3. Anthonisen NR, Manfreda J, Warren CP, et al. Antibiotic therapy in exacerbations of chronic obstructive pulmonary disease. Ann Intern Med. 1987 Feb; 106 (2):196-204.

4. Yang S, Tan KL, Devanand A, et al. Acute exacerbation of COPD requiring admission to the intensive care unit. Respirology. 2004 Nov;9(4):543-9. DOI:10.1111/j.1440-1843.2004.00615.x

5. Wang CS, FitzGerald JM, Schulzer M, et al. Does this dyspneic patient in the emergency department have congestive heart failure? JAMA. 2005 Oct 19;294 (15): 1944-56. DOI:10.1001/jama.294.15.1944.
6. Sin DD, McAlister FA, Man SF, Anthonisen NR. Contemporary management of chronic obstructive pulmonary disease: scientific review. JAMA. 2003 Nov 5;290 (17): 2301-12. DOI: 10.1001/jama. 290. 17. 2301

7. Remes J, Miettinen H, Reunanen A, Pyörälä K. Validity of clinical diagnosis of heart failure in primary health care. Eur Heart J. 1991 Mar;12(3):315-21.

8. Wheeldon NM, MacDonald TM, Flucker CJ, et al. Echocardiography in chronic heart failure in the community. Q J Med. 1993 Jan; 86 (1):17-23.

9. Render ML, Weinstein AS, Blaustein AS. Left ventricular dysfunction in deteriorating patients with chronic obstructive pulmonary disease. Chest 1995: 107:162 - 168 .

10. McCllough PA, Hollander JE, Nowak RM, Storrow AB, Duc P, Omland T, McCord J, Herrmann HC, Steg PG, Westheim A, Knudsen LW, Abraham WT, Lamba $\mathrm{S}$, Wu AH, Perez A, Clopton P, Krishnaswany P, Kazanegra R, Maisel AS. Uncovering heart failure in patients with a history of pulmonary disease: rationale for the early use of B-type natriuretic peptide in the emergency department. AcadEmerg Med 2003; 10: $198-204$.

11. Maisel A, Hollander JE, Guss D, et al. Primary results of the Rapid Emergency Department Heart Failure Outpatient Trial (REDHOT). A multicenter study of B-type natriuretic peptide levels, emergency department decision making, and outcomes in patients presenting with shortness of breath. J Am Coll Cardiol. 2004 Sep 15;44(6):1328-33. DOI:10.1016/j. jacc. 2004.06.015

12. Maisel AS, Krishnaswamy P, Nowak RM, et al. Rapid measurement of B-type natriuretic peptide in the emergency diagnosis of heart failure. N Engl J Med. 2002 Jul 18;347(3):161-7. DOI:10.1056/NEJMoa 020233

13. Maisel AS. The diagnosis of acute congestive heart failure: role of BNP measurements. Heart Fail Rev. 2003 Oct; 8(4):327-34.

14. Januzzi JL Jr, Camargo CA, Anwaruddin S, et al. The N-terminal Pro-BNP investigation of dyspnea in the emergency department (PRIDE) study. Am J Cardiol. 2005 Apr 15;95(8):948-54. DOI: 10.1016/j. amjcard. 2004.12.032 


\section{Original Research Article}

15. McCullough PA, Nowak RM, McCord J, Hollander JE, Herrmann HC, Steg PG, Duc P, Westheim A, Omland $\mathrm{T}$, Knudsen $\mathrm{CW}$ et al. B-type natriuretic peptide and clinical judgment in emergency diagnosis of heart failure: analysis from Breathing Not Properly (BNP) Multinational Study. Circulation 2002; 106: 416 -422 .

16. Cabanes L, Richaud-Thiriez B, Fulla Y, Heloire F, Vuillemard C, Weber S, Dusser D. Brain natriuretic peptide blood levels in the differential diagnosis dyspnea. Chest 2001; 120: 2047—2051.

17. Yap LB, Mukherjee D, Timms PM, Ashrafian H. Coghlan JG. Natriuretic peptides, respiratory disease and the right heart. Chest 2004; 126: $1330-1336$.

18. Phua J, Lim TK, Lee KH. B-type natriuretic peptide: issues for the intensivist and pulmonologist. Crit Care Med. 2005 Sep;33(9):2094-13.

19. Light RW, George RB. Serial pulmonary function in patients with acute heart failure. Arch Intern Med. 1983 Mar; 143 (3):429-33.

20. Cabanes LR, Weber SN, Matran R, et al. Bronchial hyperresponsiveness to methacholine in patients with impaired left ventricular function. N Engl J Med. 1989 May 18;320(20):1317-22. DOI:10.1056/NEJM 19890 5183202005

21. Pison C, Malo JL, Rouleau JL, Chalaoui J, Ghezzo $\mathrm{H}$, Malo J. Bronchial hyperresponsiveness to inhaled methacholine in subjects with chronic left heart failure at time of exacerbation and after increasing diuretic therapy. Chest 1989; 96: $230-35$.

22. Wijnhoven HA, Kriegsman DM, HesselinkAE, et al. Determinants of different dimensions of disease severity in asthma and COPD : pulmonary function and health-related quality of life. Chest. 2001 Apr;119 (4): 1034-42.
23. Singh SJ, Sodergren SC, Hyland ME, et al. A comparison of three disease-specific and two generic health-status measures to evaluate the outcome of pulmonary rehabilitation in COPD. Respir Med. 2001 Jan; 95 (1):71-7. DOI:10.1053/rmed.2000.0976

24.Herlitz J, Wiklund I, Sjoland H, Karlson BW, Karlsson T, Haglid M, et al. Relief of symptoms and improvement of quality of life five years after coronary artery bypass grafting in relation to preoperative ejection fraction. Qual Life Res 2000; 9: 467-476.

25. Arnold R, Ranchor AV, Koëter $\mathrm{GH}$, et al. Consequences of chronic obstructive pulmonary disease and chronic heart failure: the relationship between objective and subjective health. Soc Sci Med. 2005 Nov;61(10):2144-54. DOI:10.1016/j.socscimed.2005. 04.025

26. Rector TS, Anand IS, Cohn JN. Relationships between clinical assessments and patients' perceptions of the effects of heart failure on their quality of life. J Card Fail. 2006 Mar;12(2):87-92. DOI:10.1016/j. cardfail. 2005. 10.002

27. Funk GC, Lang I, Schenk P, et al. Left ventricular diastolic dysfunction in patients with COPD in the presence and absence of elevated pulmonary arterial pressure. Chest. 2008 Jun;133(6):1354-1359. doi: 10. 1378 /chest.07-2685. Epub 2008 Mar 13.

28. Suchoń E, Tracz W, Podolec P, Pieculewicz M, Płazak W, Prokop A, Nalepa P. Evaluation of Left ventricular function in patients with Chronic obstructive pulmonary disease. Pol Arch Med Wewn 2007 March;117(3):86-90.

29.A.K. Poddar, B.N. Chakraborti, J.L. Ghosh, S. Nandy and S. Hazra.Assessment of Left ventricular function in patients of Chronic obstructive pulmonary disease. Indian Journal of Tuberculosis 1997 Oct; 44 (4): 181-3.

\section{How to cite this article?}

Saha B Kr, Sarkar D, Sarkar L, Bandyopadhyay R. Left ventricular dysfunction in chronic obstructive pulmonary disease. Int J Med Res Rev 2018; 6(07):385-390. doi:10.17511/ijmrr.2018.i07.08. 